\title{
Recent progress of bulk heterojunction solar cells based on small-molecular donors
}

\author{
HUANG QiuLiu \& LI HongXiang* \\ Shanghai Institute of Organic Chemistry, Chinese Academy of Sciences, Shanghai 200032, China
}

Received March 13, 2013; accepted April 9, 2013; published online June 17, 2013

\begin{abstract}
Organic bulk heterojunction (BHJ) solar cells based on small molecular donors have received great attentions recently, because small molecules possess the merits of high purity, well-defined molecular structures, definite molecular weights and high charge carrier mobility. The highest power conversion efficiency (PCE) of BHJ solar cells based on small molecular donors and fullerene derivative acceptors has reached $7.38 \%$. In this review, we will briefly summarize the development of small molecular donor based BHJ solar cells in the past two years. These results suggest that small molecular donors are promising candidates for high efficiency BHJ solar cells.
\end{abstract}

small molecular donors, organic solar cells, organic electronics, power conversion efficiency

Citation: Huang Q L, Li H X. Recent progress of bulk heterojunction solar cells based on small-molecular donors. Chin Sci Bull, 2013, 58: 2677-2685, doi: $10.1007 / \mathrm{s} 11434-013-5930-\mathrm{z}$

Due to the environmental constraints and the predicatable exhaustion of fossil energy resources, it is one of the major challenges in the 21 st century to find clean and renewable energy. Solar energy which has the potential to act as renewable and clean energy sources is believed one of the promising and long term alternatives to replace fossil energy in the future. Currently, solar cells based on silicon have been practically applied, however, the high cost hinders their wide applications. Comparing with the well-studied silicon solar cells, photovoltaic devices based on organic semiconductors have attracted great attentions recently because they can be fabricated on flexible substrate with large scale at low-cost $[1,2]$.

In this review, we will mainly focus on the development of organic BHJ solar cells. Organic BHJ solar cells consist of electrodes (cathode and anode), donor and acceptor blended active layer and substrate. Based on the donor used into solar cells, they can be briefly divided into two classes, polymer donor solar cells and small molecular donor solar

*Corresponding author (email: lhx@mail.sioc.ac.cn) cells. Currently, the polymer donor solar cells have made great progress [3-7], and the highest power conversion efficiency (PCE) reported in literatures has been over $8 \%[8,9]$. In spite of the high performance, there are disadvantages for polymer donors [10], for instance, the high molecular weight dispersity, the batch to batch reproducibility, and so on. On the other hand, small molecular donors do not have the drawbacks mentioned above. In contrast, they have high purity, well-defined molecular structures, definite molecular weights, as well as high charge carrier mobility [11]. As a result, small molecular donors have attracted more and more attentions for photovoltaic applications recently and the highest PCE of BHJ devices based on small molecular donors has reached $7.38 \%$ [12].

Considering several reviews have summarized the application of small molecular donors in BHJ solar cells [13-21], in the present review, we will mainly focus on the development of small molecular donor BHJ solar cells in the past two years. The review will classify the donors based on their device fabrication technique. And the principle of organic solar cells which can be found in the previous reviews 
will not be discussed in here.

\section{BHJ solar cells based on solution processed small molecular donors}

Solution processing techniques are fast and cost-effective, and have been widely used in the fabrication of polymer BHJ solar cells. Recently, great progress has been made for solution processed small molecular donor based BHJ solar cells. The PCE of solution processed small molecular BHJ solar cells has matched to that of polymer BHJ solar cells. In this section, some representative solution processable small molecular donors used in BHJ solar cells are described and discussed.

\subsection{Donors with triarylamine-based electron-donating unit}

Due to the good hole transporting property and strong electron-donating ability, triarylamine units have been widely used into organic semiconductors [22]. Figure 1 shows the chemical structures of triarylamine-containing small molecular donors discussed in this section and Table 1 provides a summary of their electronic properties and solar cell characteristics.

Cho et al. [23] synthesized a fluorine-substituted benzothiadiazole-based small molecular donor $\mathbf{1}$, in which the electron-withdrawing unit mono-fluorinated benzothiadiazole core was linked with triphenylamine (TPA) groups through a $\pi$-conjugated dithiophene bridge. The BHJ solar cells with this material as the donor and $\mathrm{PC}_{71} \mathrm{BM}$ as the acceptor exhibited a PCE of $2.95 \%$ and a high open-circuit voltage $\left(V_{\text {oc }}\right)$ of $0.85 \mathrm{~V}$.

Tian and co-workers [24] synthesized three donor-accptor (D-A) type conjugated small molecules $(\mathbf{2 a}, \mathbf{2 b}$ and $\mathbf{2 c}$ ) in which electron-withdrawing moiety 2-pyran-4-ylidenemalononitrile and electron-donating group TPA were linked by different conjugation units (thiophene, triphenylamine and phenothiazine). The changes of the linkers led to different absorption spectra and bandgap of the materials. The HOMO/ LUMO energy levels of $\mathbf{2 a}, \mathbf{2 b}$ and $\mathbf{2 c}$ were $-5.04 /-3.48$, $-5.12 /-3.44$, and $-5.25 /-3.47 \mathrm{eV}$ respectively. PCEs of $0.65 \%, 0.94 \%$, and $1.31 \%$ were achieved for the BHJ devices with $\mathbf{2 a}, \mathbf{2 b}$, and $\mathbf{2 c}$ as the donors and PCBM as the acceptor, respectively. The $V_{\text {oc }}$ of $1.0 \mathrm{~V}$ obtained from $2 \mathrm{c}$ device is one of the highest values for organic solar cells based on solution processable small molecular donors.

Lee and co-workers [25] synthesized a D-A-D-A-D type small molecular donor 3a, in which TPA and naphtho[1,2-b: 5,6-b'] dithiophene (NDT) were electron donation groups and benzothiadiazole was electron-withdrawing unit. In comparison, they also synthesized compound $\mathbf{3 b}$, in which TPA donating units were removed. Experimental results showed the introduction of TPA shifted the absorption of $\mathbf{3 a}$ to longer wavelength. The HOMO/LUMO energy levels were $-5.34 /-3.34 \mathrm{eV}$ for $\mathbf{3 a}$ and $-5.16 /-3.18 \mathrm{eV}$ for $\mathbf{3 b}$. The solar cells based on molecule $\mathbf{3 a}$ and $\mathrm{PC}_{71} \mathrm{BM}$ with a $1: 4$ weight ratio reached a PCE of $2.20 \%$, two times higher than that of 3b. Later, the same research group reported two D-A-D type molecules, 5,5-bis (2-triphenylamino-3-decylthiophen-2-yl)-2,2-bithiazole (4a) and 2,5-bis (2-triphenylamino-3-decylthiophen-2-yl)thiazolo[5, 4-d]thiazole (4b) [26]. Compounds $\mathbf{4 a}$ and $\mathbf{4 b}$ had strong absorptions in the range of 300-560 nm. The HOMO/LUMO energy level was $-5.27 /-3.05 \mathrm{eV}$ for $\mathbf{4 a}$ and $-5.32 /-3.07 \mathrm{eV}$ for $\mathbf{4 b}$. The BHJ solar cells by blending $\mathbf{4 b}$ and $\mathrm{PC}_{71} \mathrm{BM}$ displayed a noticeably high $V_{\text {oc }}$ of $0.94 \mathrm{~V}$ and a PCE of $2.39 \%$. The solar cells based on $4 \mathbf{a}$ and $\mathrm{PC}_{71} \mathrm{BM}$ exhibited a higher $V_{\mathrm{oc}}$ of $0.97 \mathrm{~V}$ under optimized conditions, however due to the bad film morphology and poor charge transport capability, the PCE of $\mathbf{4 a}(1.3 \%)$ was lower than that of $\mathbf{4 b}$. Afterwards, they reported another enlarged D- $\pi$-A type conjugated small molecule 5, incorporating naphtha[1,2-b:5,6-b'] dithiophene as a rigidly fused $\pi$-conjugated central donor, thiazolothiazole as an acceptor, and triphenylamine as a terminal auxiliary donor. These donor and acceptor units were linked with 3-decylthiophene [27], which increased the solubility of $\mathbf{5}$ and facilitated solution processed photovoltaic device fabrication. In addition to solubility, compound $\mathbf{5}$ also possessed good thermal stability and well-ordered $\pi$ - $\pi$ stacking crystalline. The HOMO and LUMO energy levels of $\mathbf{5}$ were -5.23 and $-3.23 \mathrm{eV}$, respectively. Preliminary photovoltaic studies of 5 with $\mathrm{PC}_{71} \mathrm{BM}$ exhibited a maximum $\mathrm{PCE}$ of $1.44 \%$, with a short-circuit current density $\left(J_{\mathrm{sc}}\right)$ of 5.1 $\mathrm{mA} / \mathrm{cm}^{2}$, a $V_{\text {oc }}$ of $0.75 \mathrm{~V}$ and a fill factor (FF) of $38 \%$.

With the aim to lower the HOMO energy level of donors, Wang and coworkers [28] introduced electron-withdrawing groups on the $\pi$-bridged linkers. They designed and synthesized two novel D- $\pi$-A- $\pi$-D structured small molecular donors $6 \mathbf{a}$ and $6 \mathbf{b}$. 6a had $\mathrm{CN}$ groups on the $\pi$-bridged linker while $\mathbf{6 b}$ did not have the $\mathrm{CN}$ groups. Electrochemistry results showed 6a exhibited a deep HOMO energy level than that of $\mathbf{6 b}$. The BHJ solar cells based on the blending of $\mathbf{6 a}$ and PCBM displayed an impressive $V_{\text {oc }}$ up to $1.04 \mathrm{~V}$ and a PCE of $3.85 \%$, while the non-cyano substituted $\mathbf{6 b}$ yielded a $V_{\text {oc }}$ of $0.94 \mathrm{~V}$ and a PCE of $1.99 \%$.

Zhan and co-workers [29] have conducted systematical studies on triarylamine-based D-A-D type molecules with different acceptor units. Using bithiazole as acceptor unit, triphenylamine as donor unit and oligothiophenes (the numbers of thiophene units were 0,1 and 2) as bridge, they synthesized a series of compounds $\mathbf{7 a - 7 c}$. With the increasing of conjugation length of oligothiophene bridge, compound 7 exhibited boarder absorption spectra, higher extinction coefficient, and higher hole mobility. The HOMO/LUMO energy levels were $-5.42 /-2.48 \mathrm{eV}$ for $7 \mathbf{a},-5.24 /-2.84 \mathrm{eV}$ for $\mathbf{7 b}$ and $-5.22 /-2.81 \mathrm{eV}$ for $7 \mathbf{c}$. The solar cells based on 7a-7c: $\mathrm{PC}_{71} \mathrm{BM}$ also displayed increasing power conversion 

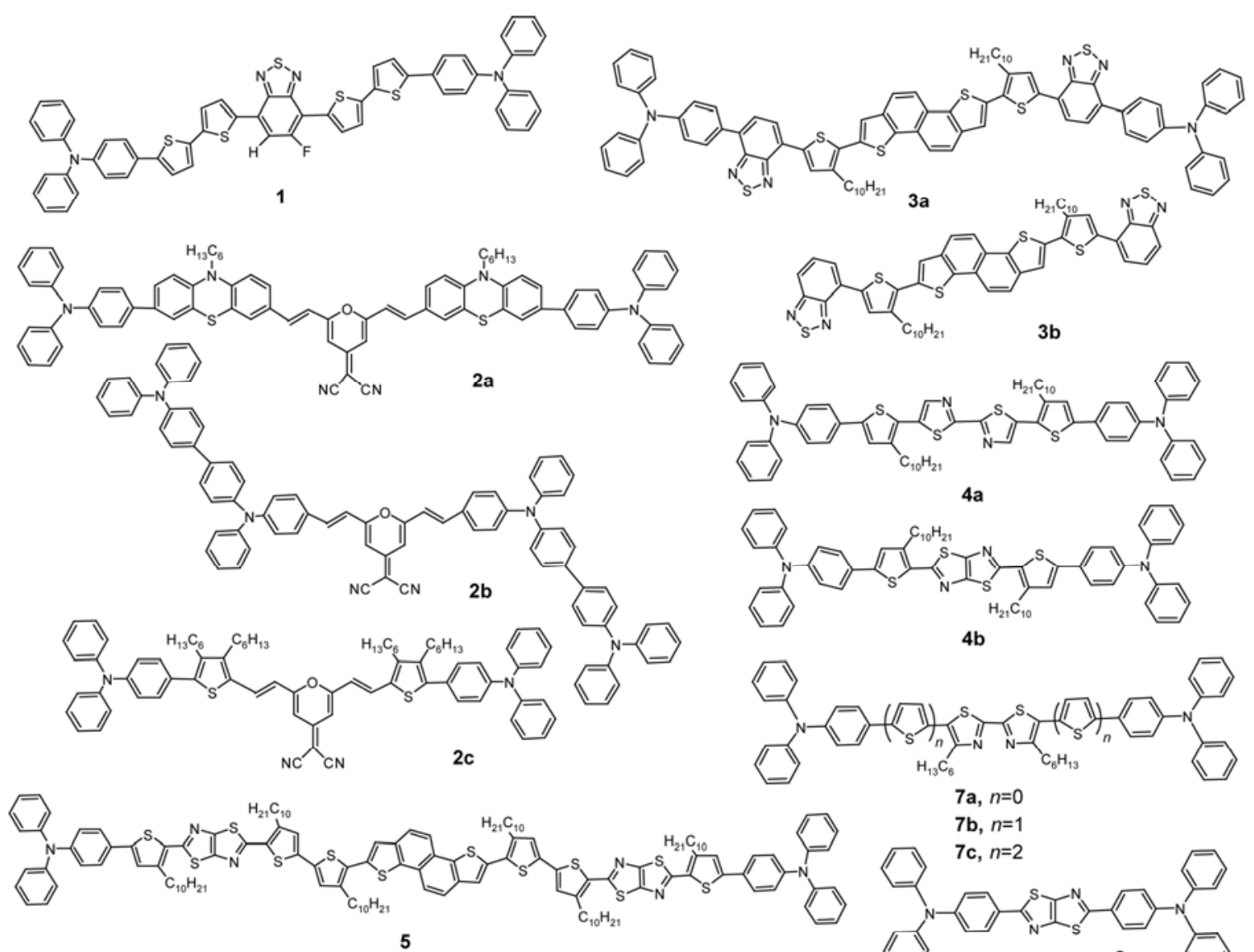

$7 \mathrm{a}, n=0$

$7 \mathrm{~b}, n=1$
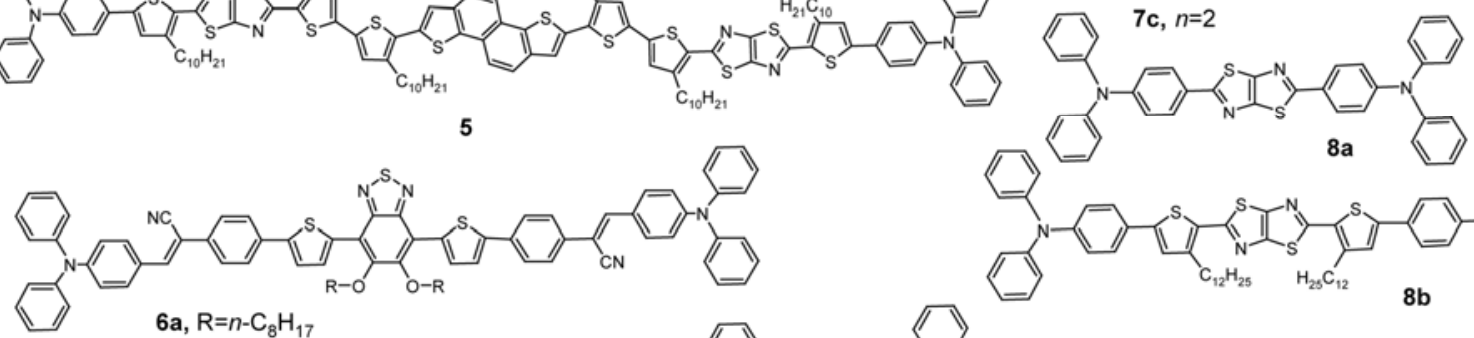

6a, $\mathrm{R}=n-\mathrm{C}_{8} \mathrm{H}_{17}$

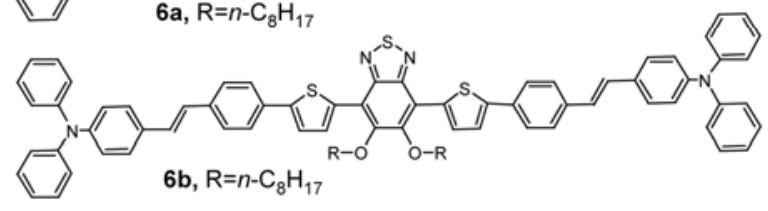

$6 \mathrm{~b}, \mathrm{R}=n-\mathrm{C}_{8} \mathrm{H}_{17}$

Figure 1 Chemical structures of solution processable small molecular donors with triarylamine-based electron-donating moiety. 
efficiency (up to $2.61 \%$ ) with the increasing of thiophene unit number. By using thiazolothiazole (TT) to replace bithiazole as acceptor unit, they prepared compounds $\mathbf{8 a - 8 c}$ [30,31]. Similar as that of $\mathbf{7 a - 7 c}$, the BHJ solar cells based on 8a-8c: $\mathrm{PC}_{71} \mathrm{BM}$ blended thin films exhibited increasing PCE up to $4.05 \%$ with the increasing of thiophene units. Later, they synthesized another series of thieno[3,4-c]pyrrole4,6-dione (TPD) containing molecules 9a-9c [32], which showed strong absorption at 460-490 $\mathrm{nm}$ and low HOMO levels $(-5.26$ to $-5.34 \mathrm{eV})$. The $\mathrm{BHJ}$ solar cells based on the blends of these molecule donors and $\mathrm{PC}_{71} \mathrm{BM}$ acceptor displayed the PCE of $2.7 \%-2.9 \%$. After thermal annealing, the PCE of $\mathbf{9 b}$ based device enhanced to $3.31 \%$.

Due to the special propeller starburst molecular structure, TPA unit is an excellent unit to construct star shaped organic semiconductors. Star shaped molecules have shown promising performance in BHJ solar cells [33]. Zhan and coworkers [34,35] synthesized two TPA-containing star shaped small molecular donors $\mathbf{1 0}$ and 11. Both compounds displayed good PCE while blending with PCBM, and the PCE of compound $\mathbf{1 0}$ reached $4.3 \%$ without any posttreatment. AFM results showed the blend film of $\mathbf{1 0}$ and $\mathrm{PC}_{71} \mathrm{BM}$ displayed typical cluster structures with nanoscale aggregated domains and a root-mean-square roughness of $0.66 \mathrm{~nm}$, which was beneficial to charge separation and enhanced the efficiency of the solar cells.

\subsection{Donors with sulfur-containing heterocycle-based electron-donating unit}

Besides triarylamine, sulfur contained heterocycles such as oligothiophenes, fused thiophenes, dithieno(3,2-b;2',3'-d) silole and benzo[1,2-b:4,5- $\left.\mathrm{b}^{\prime}\right]$ dithiophene are also commonly used as electron-donating units in the small molecular donors. Figure 2 lists the chemical structures of the donors with surfer-containing heterocycles as electron-donating moiety that discussed in this section. Their electronic properties and BHJ solar cell characteristics are summarized in Table 1.

Liu and co-workers [36] synthesized oligothiophene based small molecular donor 12. In compound 12, 3-ethylrhodanine, a dye unit, was first used as electron-withdrawing block into small molecular donors. The HOMO and LUMO energy levels as well as bandgap of $\mathbf{1 2}$ estimated from solution were $-5.00,-3.28$, and $1.72 \mathrm{eV}$, respectively. Though the solution absorption of compound $\mathbf{1 2}$ was in the range of 350-600 nm, its thin film absorption was largely red shifted and became broad (in the range of 370-750 nm). Moreover, 12 formed high quality thin film through solution processing technique. A high PCE of $6.10 \%$ was obtained by blending 12 and $\mathrm{PC}_{61} \mathrm{BM}$ as the active layer, with a $V_{\mathrm{oc}}$ of $0.92 \mathrm{~V}$ and a $J_{\mathrm{sc}}$ of $13.98 \mathrm{~mA} / \mathrm{cm}^{2}$. Later, the same group further increased the electron-donating ability by introducing benzo[1,2-b:4,5-b']dithiophene unit into the donors and synthesized compound $\mathbf{1 3}$ [12]. With the optimized weight ratio of 13 to $\mathrm{PC}_{71} \mathrm{BM}$ at 1:0.8, a $\mathrm{PCE}$ of $6.92 \%$ was obtained with a $J_{\mathrm{sc}}$ of $11.40 \mathrm{~mA} / \mathrm{cm}^{2}$, a $V_{\mathrm{oc}}$ of $0.93 \mathrm{~V}$, and a $\mathrm{FF}$ of $65.3 \%$. When $0.2 \mathrm{mg} / \mathrm{mL}$ trimethylsiloxyl terminated PDMs was added during the film-forming process, a highest PCE of $7.38 \%$ with a $V_{\text {oc }}$ of $0.93 \mathrm{~V}$ and a $J_{\text {sc }}$ of 12.21 $\mathrm{mA} / \mathrm{cm}^{2}$ was observed, which is the highest efficiency reported to date for the small molecular donor based BHJ solar cells.

Jo and co-workers [37] synthesized a series of diketopyrrolopyrrole (DPP)-based small molecules 14a, 14b and $\mathbf{1 4 c}$, in which different electron-donating units were used. Because these molecules shared same electron accepting unit (DPP), they exhibited similar LUMO energy levels. Their HOMO energy levels were effectively tuned by the different electron-donating units. The HOMO/LUMO energy levels of 14a, 14b and 14c were $-5.19 /-3.66,-5.17 /$ $-3.68,-5.31 /-3.65 \mathrm{eV}$, respectively. 14c exhibited the highest PCE among three compounds with a PCE up to $4.01 \%$, a $V_{\text {oc }}$ of $0.93 \mathrm{~V}$ and a $J_{\text {sc }}$ of $9.09 \mathrm{~mA} / \mathrm{cm}^{2}$ when it was blended with $\mathrm{PC}_{71} \mathrm{BM}$. The authors believed the higher hole mobility and the well-developed nanoscale phase-separate morphology of 14c were responsible for its high PCE though it had the largest bandgap.

Zhan and coworkers [38] synthesized series of D-A-D type DPP derivatives of $\mathbf{1 5 a}, \mathbf{1 5 b}$ and $\mathbf{1 5} \mathbf{c}$ through attaching different donor units of thiophene, selenophene, and thieno [3,2-b]thiophene to the DPP core. The LUMO energy levels of these compounds were around $-3.38 \mathrm{eV}$. Their HOMO energy levels were slightly different, which were $-5.06 \mathrm{eV}$ for $\mathbf{1 5} \mathbf{a},-5.01 \mathrm{eV}$ for $\mathbf{1 5} \mathbf{b}$ and $-4.98 \mathrm{eV}$ for $\mathbf{1 5} \mathbf{c}$, consistent with the electron-donating nature of thiophene, selenophene, and thieno[3,2-b]thiophene. The replacement of the thiophene donors with the more polarized selenophene units resulted in a balance between $a$ and $b$ direction packing and an obvious increase of the PCE from $1.90 \%$ to $2.33 \%$ with the increase of $J_{\mathrm{sc}}$ from 5.59 to $5.81 \mathrm{~mA} / \mathrm{cm}^{2}$, and $V_{\text {oc }}$ from 0.78 to $0.86 \mathrm{~V}$.

Bazan and co-workers [39] reported series of pyridal $[2,1,3]$ thiadiazole (PT)-dithieno(3,2-b; $2^{\prime}, 3^{\prime}$-d) silole (DTS) contained D-A-D-A-D type small molecular donors 16a, 16b and 16c. These materials showed similarities to the $\mathrm{D}$-A type $\pi$-conjugated copolymers in both structure and properties. The optical absorption spectrum of 16c was extending beyond $700 \mathrm{~nm}$ with a HOMO and LUMO energy level of -5.16 and $-3.60 \mathrm{eV}$. The BHJ solar cells fabricated with $16 \mathrm{c}$ as the donor and $\mathrm{PC}_{71} \mathrm{BM}$ as the acceptor component showed a $J_{\mathrm{sc}}$ above $10 \mathrm{~mA} / \mathrm{cm}^{2}$ and a PCE up to $3.2 \%$. Soon afterwards, Sun et al. [40] designed a small molecular donor 17, which was an isomer of molecule 16c. The HOMO/LUMO energy level of $\mathbf{1 7}$ was estimated to be $-5.20 /-3.60 \mathrm{eV}$ and the optical bandgap was approximately $1.5 \mathrm{eV}$. A high PCE of $4.5 \%$ was obtained by blending 17 and $\mathrm{PC}_{70} \mathrm{BM}$ composites with the blend ratio of $7: 3$. When a small percentages of solvent additive 1,8-diiodooctane was added during the film-forming process, a high PCE of 


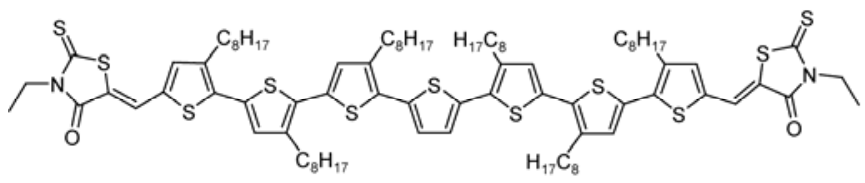

12

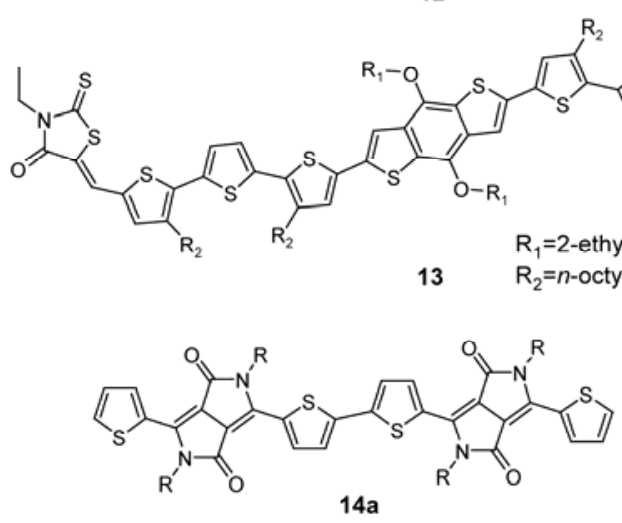

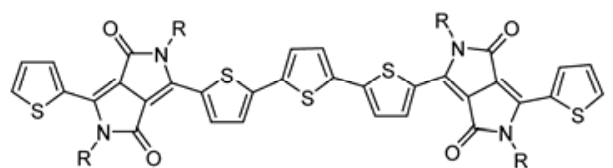

14b

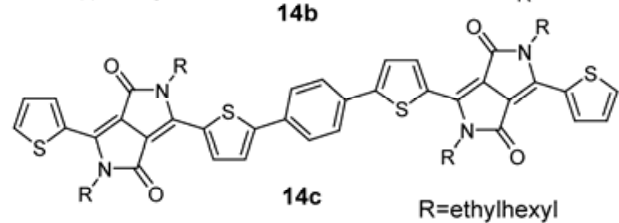

$14 \mathrm{c}$

$\mathrm{R}=$ ethylhexyl

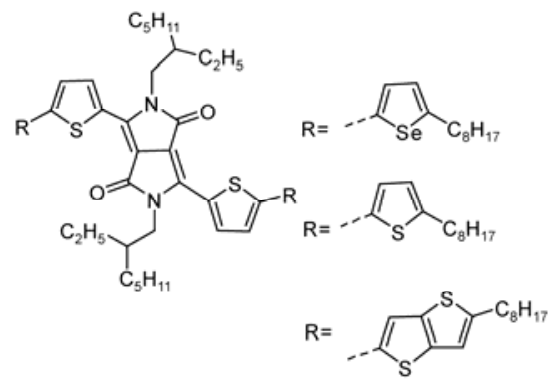

$\mathrm{R}_{2}$<smiles>[R]C1=CC=C1</smiles><smiles>C=C(S)/C=C1\SC(=S)N(CC)C1=O</smiles>

$15 a$

$15 b$

$15 \mathrm{c}$

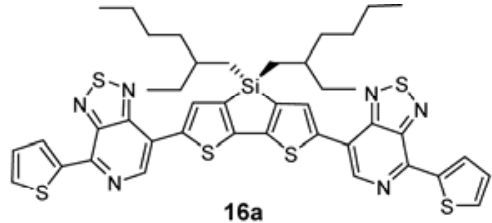

$16 a$

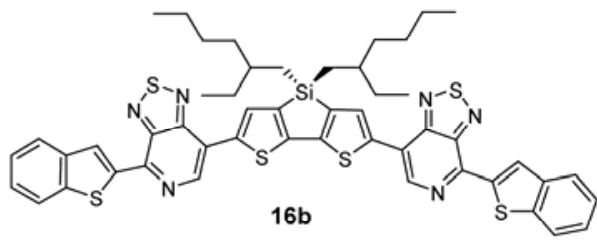

$16 \mathrm{~b}$

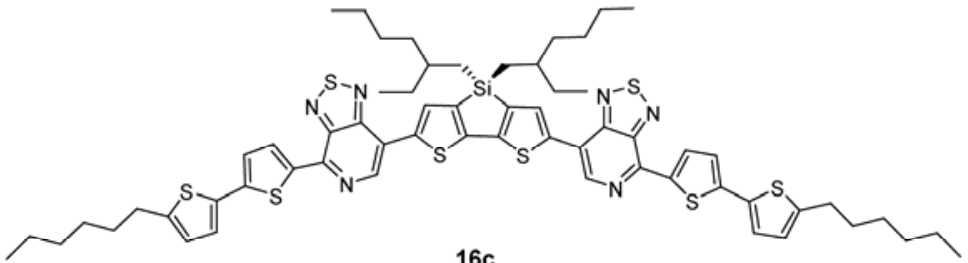

$16 \mathrm{c}$
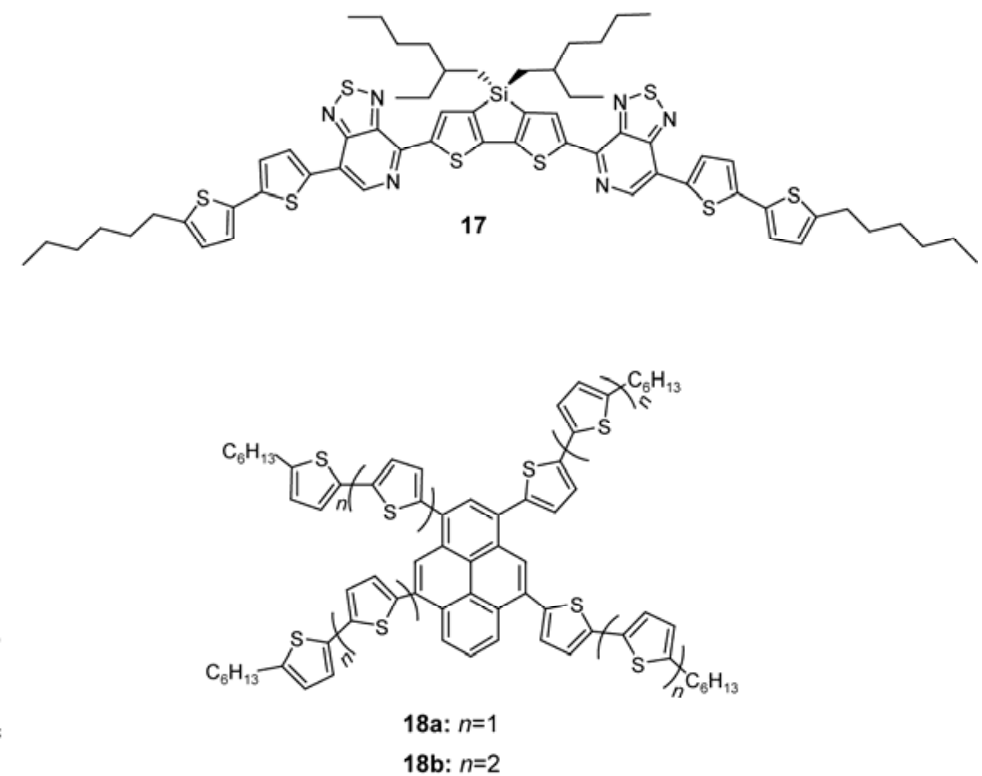

Figure 2 Chemical structures of solution processable small molecular donors with surfur-containing heterocycle-based electron-donating moiety.

$6.7 \%$ was observed. In order to deeply investigate the applications of PT unit on solar cell donors, the same group synthesized series $\mathrm{D}^{1}-\mathrm{PT}-\mathrm{D}^{2}-\mathrm{PT}-\mathrm{D}^{1}$ type small molecular donors [41], they found the changes of the end-capping $\mathrm{D}^{1}$ units allowed for the fine control over electronic energy levels of donors both in solution and in solid state, and the alterations to the core donor $\mathrm{D}^{2}$ led to readily identifiable changes in all properties studied. Further, they particularly studied the effect of the position of pyridine $\mathrm{N}$ atom on the PT unit [42]. Experimental results showed that the change of the position of the pyridyl $\mathrm{N}$-atoms varied the dipoledipole interactions of molecules and the self-assemble behaviors of molecules in films, which led to different device performance.

$\pi$-Conjugated disk-shaped molecules such as pyrene and hexa-peri-hexabenzocoronene can form highly ordered onedimensional stacks through intermolecular $\pi-\pi$ interactions [43], which provides a pathway for carrier transport. Kimura and co-workers [44] synthesized disk-shaped small molecular donors 18a and 18b, which were composed of a planar pyrene core and oligothiophenes arms. The optical and electronic properties of the disc molecules could be tuned by changing the length of oligothiophenes. The solar cells fabricated with these molecules as electron donor components exhibited a PCE of $2.6 \%$.

\subsection{Porphyrin-based donor}

Porphyrin, as a synthetically tractable analogue of chlorophylls, has the merits of extensively $\pi$-conjugated systems, 
Table 1 Optical and electronic properties, and mobilities of solution processable small molecular donors and their BHJ solar cells characteristics

\begin{tabular}{|c|c|c|c|c|c|c|c|c|c|c|}
\hline Donor & $\begin{array}{l}\text { HOMO } \\
(\mathrm{eV})\end{array}$ & $\begin{array}{c}\text { LUMO } \\
(\mathrm{eV})\end{array}$ & $\begin{array}{c}\text { Bandgap } \\
(\mathrm{eV})\end{array}$ & $\begin{array}{c}\text { Mobility }{ }^{\mathrm{a})} \\
\left(\mathrm{cm}^{2} /(\mathrm{V} \mathrm{s})\right)\end{array}$ & $\begin{array}{l}\text { Active layer } \\
\text { (ratio, w/w) }\end{array}$ & $\begin{array}{c}J_{\mathrm{sc}} \\
\left(\mathrm{mA} / \mathrm{cm}^{2}\right)\end{array}$ & $\begin{array}{l}V_{\mathrm{oc}} \\
(\mathrm{V})\end{array}$ & $\begin{array}{l}\mathrm{FF} \\
(\%)\end{array}$ & $\begin{array}{l}\text { PCE } \\
(\%)\end{array}$ & Ref \\
\hline 1 & -5.07 & -3.68 & 1.39 & $6.62 \times 10^{-6}$ & 1:PC ${ }_{71} \mathrm{BM}(1: 4)$ & 8.51 & 0.85 & 41 & 2.95 & 23 \\
\hline $2 \mathrm{c}$ & -5.25 & -3.47 & 1.78 & $7.47 \times 10^{-5}$ & 2c:PCBM (1:2) & 3.85 & 1.0 & 34 & 1.31 & 24 \\
\hline $3 \mathbf{a}$ & -5.34 & -3.34 & 1.96 & $6.0 \times 10^{-5^{*}}$ & 3a: $\mathrm{PC}_{71} \mathrm{BM}(1: 4)$ & 6.18 & 0.95 & 37 & 2.20 & 25 \\
\hline $4 b$ & -5.32 & -3.07 & 2.25 & - & $4 \mathbf{b}: \mathrm{PC}_{61} \mathrm{BM}(1: 3)$ & 6.49 & 0.94 & 39 & 2.39 & 26 \\
\hline 5 & -5.23 & -3.23 & 2.00 & $2.0 \times 10^{-6}$ & 5:PC ${ }_{71} \mathrm{BM}(1: 2)$ & 5.10 & 0.75 & 38 & 1.44 & 27 \\
\hline $6 a$ & -5.32 & -3.33 & 1.99 & - & 6a: $\mathrm{PC}_{61} \mathrm{BM}(1: 2)$ & 11.2 & 1.04 & 33 & 3.85 & 28 \\
\hline $7 c$ & -5.22 & -2.81 & 2.41 & $3.6 \times 10^{-4}$ & 7c: $\mathrm{PC}_{71} \mathrm{BM}(1: 4)$ & 7.72 & 0.84 & 40.2 & 2.61 & 29 \\
\hline $8 \mathbf{b}$ & -5.32 & -2.67 & 2.17 & $7.7 \times 10^{-4^{*}}$ & 8b: $\mathrm{PC}_{71} \mathrm{BM}(1: 4)$ & 7.70 & 0.91 & 47.3 & 3.31 & 30 \\
\hline $9 \mathrm{c}$ & -5.28 & -2.75 & 2.53 & $1.01 \times 10^{-5}$ & 9c: $\mathrm{PC}_{71} \mathrm{BM}(1: 4)$ & 9.74 & 0.85 & 47 & 4.05 & 32 \\
\hline 10 & -5.28 & -3.11 & - & $6.4 \times 10^{-4^{*}}$ & 10: $\mathrm{PC}_{61} \mathrm{BM}(1: 3)$ & 9.51 & 0.87 & 52 & 4.30 & 34 \\
\hline 11 & -5.28 & -3.43 & 1.95 & $1.5 \times 10^{-3}$ & 11: $\mathrm{PC}_{71} \mathrm{BM}(1: 2)$ & 7.30 & 0.88 & 56 & 3.60 & 35 \\
\hline 12 & -5.00 & -3.28 & 1.72 & $1.5 \times 10^{-4}$ & 12: $\mathrm{PC}_{61} \mathrm{BM}(1: 0.5)$ & 13.98 & 0.92 & 47.4 & 6.10 & 36 \\
\hline 13 & -5.02 & -3.27 & 1.75 & $2.47 \times 10^{-4}$ & 13: $\mathrm{PC}_{71} \mathrm{BM}(1: 0.8)$ & 12.21 & 0.93 & 65 & 7.38 & 12 \\
\hline $14 c$ & -5.31 & -3.65 & 1.66 & $8.8 \times 10^{-5}$ & 14c: $\mathrm{PC}_{71} \mathrm{BM}(1.25: 1)$ & 9.09 & 0.93 & 47 & 4.01 & 37 \\
\hline $15 b$ & -5.01 & -3.38 & 1.63 & $3.0 \times 10^{-4}$ & 15b: $\mathrm{PC}_{61} \mathrm{BM}(3: 1)$ & 5.81 & 0.86 & 46 & 2.33 & 38 \\
\hline $16 \mathrm{c}$ & -5.16 & -3.60 & 1.56 & $1.5 \times 10^{-6}$ & 16c: $\mathrm{PC}_{71} \mathrm{BM}(3: 2)$ & 10.9 & 0.70 & 42 & 3.20 & 39 \\
\hline 17 & -5.20 & -3.60 & 1.50 & $6.0 \times 10^{-3^{*}}$ & 17: $\mathrm{PC}_{70} \mathrm{BM}(7: 3)$ & 14.4 & 0.78 & 59.3 & 6.70 & 40 \\
\hline $18 b$ & -5.07 & -2.71 & 2.36 & - & 18b:PC ${ }_{71} \mathrm{BM}(1: 4)$ & 8.8 & 0.83 & 36 & 2.60 & 44 \\
\hline 19 & -5.20 & -3.90 & 1.30 & $7.4 \times 10^{-6}$ & 19: $\mathrm{PC}_{71} \mathrm{BM}(1: 3)$ & 9.46 & 0.85 & 50 & 4.02 & 46 \\
\hline 20 & -5.18 & -3.39 & - & $1.6 \times 10^{-4}$ & 20:PC ${ }_{61} \mathrm{BM}(1: 1)$ & 11.88 & 0.80 & 50.2 & 4.78 & 47 \\
\hline
\end{tabular}

a) The mobility values marked with “*” were measured by organic field effect transistor (OFET) method; while others without "**” marked were tested by space charge limited current (SCLC) model.

fast electron transportation, high absorption coefficient and tunable physicochemical properties [45]. Peng and coworkers [46] synthesized a conjugated A-D-A type porphyrin small molecule 19, in which the typical acceptor 2,1,3benzothiadiazole (BT) end-capped with 3-hexylthienyl was linked by an ethynylene bridge to a porphyrin core (Figure 3 ). The HOMO and LUMO energy levels of 19 were -5.20 and $-3.90 \mathrm{eV}$, respectively. The solution processed solar cells by blending 19 and $\mathrm{PC}_{71} \mathrm{BM}$ showed a $J_{\mathrm{sc}}$ of 9.46 $\mathrm{mA} / \mathrm{cm}^{2}$, a $V_{\text {oc }}$ of $0.85 \mathrm{~V}$ and a $\mathrm{FF}$ of $50 \%$, resulting in a
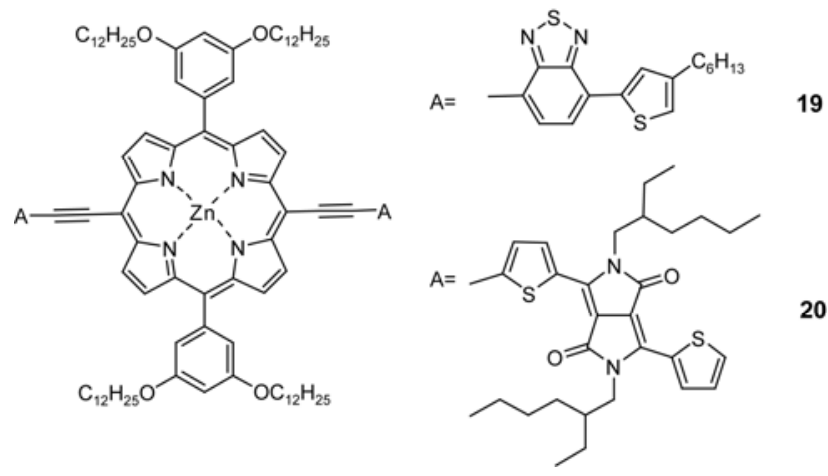

Figure 3 Chemical structure of solution processable porphyrin-based small molecular donors.
PCE of $4.02 \%$. Most recently, the same research group reported another conjugated porphyrin small molecular donor 20 in which DPP was used as the electron-deficient group [47] (Figure 3). The HOMO and LUMO energy levels of 20 were -5.18 and $-3.39 \mathrm{eV}$, respectively. Though compound 20 had lager bandgap comparing with 19, the PCE of the devices based on $\mathbf{2 0}$ and $\mathrm{PC}_{61} \mathrm{BM}$ was up to $4.78 \%$, with a $V_{\mathrm{oc}}$ of $0.80 \mathrm{~V}$, a $J_{\mathrm{sc}}$ of $11.88 \mathrm{~mA} / \mathrm{cm}^{2}$ and a $\mathrm{FF}$ of $50.2 \%$, which is one of the highest PCE for BHJ solar cells based on the solution-processable porphyrin small molecules as the donors and PCBM as the acceptor reported so far. The higher PCE of $\mathbf{2 0}$ was ascribed to its high hole mobility and smoother film morphology.

\section{BHJ solar cells based on vacuum-deposited small molecules as donors}

Though vacuum deposition is less cost-effective in comparison with solution processing, it not only can form better ordered morphology and usually lead to higher PCE, but also is very helpful to understand the basic scientific questions of solar cells [20]. The Würthner and Meerhoze research groups [48] investigated the performance of the merocyamine dyes based BHJ solar cells in which the active 
layer was prepared by vacuum-deposition and solutionprocessing using the similar device structures. The highest PCE of $4.9 \%$ was achieved by the vacuum-prepared device, almost two times higher that of solution-processed device (PCE of 2.5\%). The authors concluded that there was an efficient charge-carrier generation and/or reduced recombination in the solar cells with evaporated active layers. In addition, as a result of more favorable morphology in vacuum-deposited layer, exciton separation can occur more effectively, leading to higher $J_{\text {sc }}$ and PCE values. Afterwards, they optimized a simple stack BHJ solar cell based on the merocyamine dye 21 (Figure 4), and a high PCEs up to $6.1 \%$ was obtained [49].

Squaraine (SQ) dyes, especially 2,4-bis[4-(N,N-diisobutylamino)-2, 6-dihydroxyphenyl] squaraine (22) (Figure 4) was another promising material for future application in organic photovoltaic. Sasabe and co-workers [50] demonstrated high efficiency BHJ solar cells based on squaraine dye 22 as a donor and fullerene $\mathrm{C}_{70}$ as an acceptor by vacuum deposition, and a highest PCE of $6.3 \%$ with a $J_{\text {sc }}$ of $13.7 \mathrm{~mA} / \mathrm{cm}^{2}$, a $V_{\mathrm{oc}}$ of $0.87 \mathrm{~V}$ and a FF of $53 \%$ was observed.

From the study of dye-sensitized solar cells, Lin et al. [51] found that organic dyes with a donor-acceptor-acceptor (D-A-A) molecular architecture possessed both a smaller bandgap and lower HOMO level than their analogs. For this reason, they synthesized three tailor-made D-A-A-type molecules 23a, 23b, and 23c as donor materials for smallmolecular BHJ solar cells [52], in which various electrondonating moieties were connected to an electron-withdrawing dicyanovinylene moiety through another electron-accepting 2,1,3-benzothiadiazole block. The adoption of thiophenebased donor facilitated the $\pi$-electron delocalization and the formation of quinoidal mesomeric structures over the conjugated backbone. The HOMO/LUMO energy levels of $\mathbf{2 3}$ were around $-5.35 /-3.30 \mathrm{eV}$. Through fine-tuning the thickness as well as the blend ratio of the active layers in the BHJ layer, vacuum-deposited hybrid planar-mixed heterojunction devices utilizing 23c as the donor and $\mathrm{C}_{70}$ as the acceptor showed the best performance with a PCE of $6.6 \%$, along with a $V_{\mathrm{oc}}$ of $0.93 \mathrm{~V}$, a $J_{\mathrm{sc}}$ of $13.48 \mathrm{~mA} / \mathrm{cm}^{2}$, and a FF of $53 \%$.

Bäuerle and co-workers [53] synthesized a series of terminally dicyanovinyl (DCV)-substituted oligothiophenes. The structural fine-tuning of these A-D-A-type oligothiophenes led to highly efficient materials with sufficiently
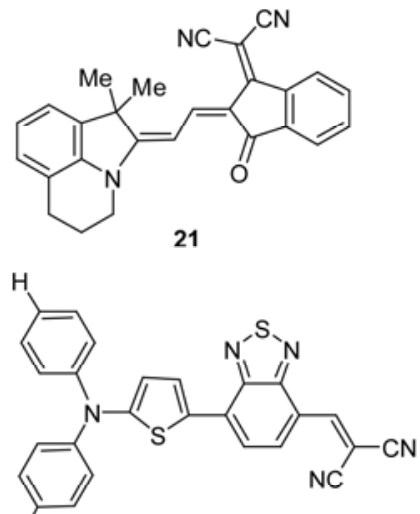

23a
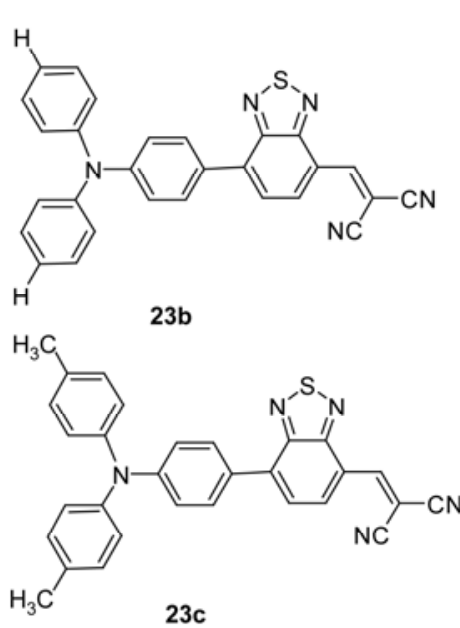

$23 c$

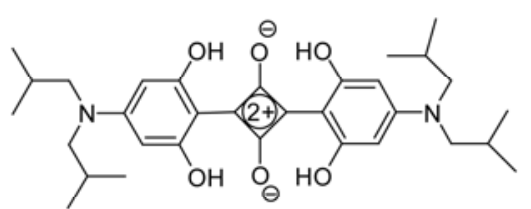

22<smiles>CCCCCCc1c(-c2ccc(-c3sc(-c4ccc(C=C(C#N)C#N)s4)c(C)c3CCCCC)s2)sc(-c2ccc(C=C(C#N)C#N)s2)c1C</smiles>

24<smiles>[CH2+]c1c(-c2ccc(C=C(C#N)C#N)s2)sc(-c2ccc(-c3sc(-c4ccc(C=C(C#N)C#N)s4)c(C)c3CCCC)s2)c1C</smiles>

$25 a$<smiles>CCCCCc1c(-c2ccc(-c3sc(-c4ccc(C=C(C#N)C#N)[se]4)c(C)c3CCCCC)s2)sc(-c2ccc(C=C(C#N)C#N)s2)c1C</smiles>

$25 b$<smiles>[CH2+]c1c(-c2ccc(C=C(C#N)C#N)[se]2)sc(-c2ccc(-c3sc(-c4ccc(C=C(C#N)C#N)s4)c(C)c3CCCC)s2)c1C</smiles>

$25 c$

Figure 4 Vacuum-deposited small molecular donors. 
Table 2 Optical and electronic properties and mobilities of vacuum deposited small molecular donors and their BHJ solar cells characteristics

\begin{tabular}{|c|c|c|c|c|c|c|c|c|c|c|}
\hline Donor & $\begin{array}{c}\text { HOMO } \\
(\mathrm{eV})\end{array}$ & $\begin{array}{c}\text { LUMO } \\
(\mathrm{eV}) \\
\end{array}$ & $\begin{array}{c}\text { Bandgap } \\
(\mathrm{eV})\end{array}$ & $\begin{array}{l}\text { Mobility }{ }^{\mathrm{a})} \\
\left(\mathrm{cm}^{2} /(\mathrm{V} \mathrm{s})\right)\end{array}$ & $\begin{array}{c}\text { Donor:Acceptor } \\
\text { (ratio, w/w) }\end{array}$ & $\begin{array}{c}J_{\mathrm{sc}} \\
\left(\mathrm{mA} / \mathrm{cm}^{2}\right) \\
\end{array}$ & $\begin{array}{l}V_{\text {oc }} \\
(\mathrm{V}) \\
\end{array}$ & $\begin{array}{l}\mathrm{FF} \\
(\%) \\
\end{array}$ & $\begin{array}{l}\mathrm{PCE} \\
(\%) \\
\end{array}$ & Ref \\
\hline 21 & -5.75 & -3.60 & - & $2 \times 10^{-4}$ & $\mathbf{2 1}: \mathrm{C}_{60}(9: 11)$ & 12.6 & 0.96 & 47 & 6.10 & 49 \\
\hline 22 & -5.30 & -3.60 & 1.70 & $9.81 \times 10^{-5}$ & $22: \mathrm{C}_{70}(1: 5)$ & 13.7 & 0.87 & 53 & 6.30 & 50 \\
\hline $23 c$ & -5.43 & -3.35 & 1.66 & $6.49 \times 10^{-5}$ & 23c: $\mathrm{C}_{70}(1: 1.6)$ & 13.48 & 0.93 & 53 & 6.60 & 52 \\
\hline 24 & -5.62 & -3.73 & 1.89 & - & $\mathbf{2 4}: \mathrm{C}_{60}(2: 1)$ & 11.1 & 0.97 & 49 & 5.20 & 53 \\
\hline $25 a$ & -5.61 & -3.74 & 1.87 & - & 25a: $\mathrm{C}_{60}(2: 1)$ & 5.5 & 0.99 & 48 & 3.09 & 54 \\
\hline
\end{tabular}

a) The mobility values were tested by SCLC model.

electronic and charge transport properties. The optimization of BHJ solar cells using a $40 \mathrm{~nm}$ active layer of DCV5T (24) and $\mathrm{C}_{60}$ in a $2: 1$-ratio resulted in a conversion efficiency of $5.2 \%$, with a $J_{\mathrm{sc}}$ of $11.1 \mathrm{~mA} / \mathrm{cm}^{2}$, a $V_{\text {oc }}$ of $0.97 \mathrm{~V}$ and a FF of $49 \%$. Further, they introduced selenophene into oligothiophenes and synthesized series of small molecular donors 25a, 25b and 25c [54]. The replacement of thiophene units by selenophenes resulted in a bathochromic shift of the longest wavelength absorption band with concomitant increase of the molar extinction coefficient. The different positions of selenophene slightly changed the HOMO/LUMO energy levels of $\mathbf{2 5}$. The vacuum-deposited BHJ solar cells fabricated with 25a as the donor and $\mathrm{C}_{60}$ as the acceptor displayed the highest performance among the three molecules with a PCE of 3.09 , a $V_{\text {oc }}$ of $0.99 \mathrm{~V}$, a $J_{\text {sc }}$ of 5.5 $\mathrm{mA} / \mathrm{cm}^{2}$ and a FF of $48 \%$, which was slightly lower than DCV5T based BHJ solar cells.

\section{Conclusions}

In this review, we have given an overview on the progress of small molecular donor BHJ solar cells in the past two years. The performance of BHJ solar cells is a combination of many factors, such as the molecular packing, the energy levels of donors and acceptors, the hole/electron mobility, the quality of thin films and so on. In Tables 1 and 2, we provide the useful information of these representatively new small-molecular donors and their photovoltaic performance with detailed device parameters, aiming to give an impression on the relationship of the performance of the BHJ solar cells with these factors. The results show that the low bandgap and the matching energy levels with the corresponding acceptor of the donors, the high ordered film morphology, and the fast exciton separation and carrier transportation in the photoactive layers are beneficial for high-efficiency BHJ solar cells. Solution processing and vacuum deposition are two common techniques for the fabrication of small molecular donor BHJ solar cells. Both techniques have their merits, solution processing is a relatively fast and low-cost method but often leads to less favorable morphology, while vacuum deposition brings ordered layers and high PCE but is more costly. Either way to choose should be based on the properties of the molecules.
To further improve the PCE of small molecular donor BHJ solar cells, two issues should be paid more efforts. One is to design and synthesize new type of donor materials. In the new materials, we should consider not only the electron donating/withdrawing abilities of the conjugation units, the HOMO/LUMO energy levels and the carrier mobility of the materials, but also their self-assemble behavior and dipole-dipole interactions. The other is to optimize the device fabrication condition. In this process, the important role of solvent additives is worth us to pay more and more attentions. Though the effciency of small molecular donor BHJ solar cells is not as high as that of polymer BHJ solar cells and many basic scientific questions in small molecular donor BHJ solar cells are unsolved at current stage, we strong believe great progress will be made on small molecular donor BHJ solar cells in the years to come.

This work was supported by the National Natural Science Foundation of China (21190031).

1 Thompson B C, Fréchet J M. Polymer-fullerene composite solar cells. Angew Chem Int Ed, 2008, 47: 58-77

2 Heeger A J. Semiconducting polymers: The third generation. Chem Soc Rev, 2010, 39: 2354-2371

3 Zhao X L, Yang D L, Lv H Y, et al. New benzotrithiophene derivative with a broad band gap for high performance polymer solar cells. Pol Chem, 2013, 4: 57-60

4 Chen G Y, Cheng Y H, Chou Y J, et al. Crystalline conjugated polymer containing fused 2,5-di(thiophen-2-yl)thieno[2,3-b]thiophene and thieno[3,4-c]pyrrole-4,6-dione units for bulk heterojunction solar cells. Chem Commun, 2011, 47: 5064-5066

5 Liu F, Gu Y, Wang C, et al. Efficient polymer solar cells based on a low bandgap semi-crystalline DPP polymer-PCBM blends. Adv Mater, 2012, 24: 3947-3951

$6 \mathrm{Xu} \mathrm{Y} \mathrm{X,} \mathrm{Chueh} \mathrm{C} \mathrm{C,} \mathrm{Yip} \mathrm{H} \mathrm{L,} \mathrm{et} \mathrm{al.} \mathrm{Improved} \mathrm{charge} \mathrm{transport} \mathrm{and}$ absorption coefficient in indacenodithieno[3,2-b]thiophene-based ladder-type polymer leading to highly efficient polymer Solar Cells. Adv Mater, 2012, 24: 6356-6361

7 Yang T B, Qin D H, Lan L F, et al. Inverted polymer solar cells with a solution-processed zinc oxide thin film as an electron collection layer. Sci China Chem, 2012, 55: 755-759

8 Chen H C, Chen Y H, Liu C C, et al. Prominent short-circuit currents of fluorinated quinoxaline-based copolymer solar cells with a power conversion efficiency of 8.0\%. Chem Mater, 2012, 24: 4766-4772

9 Chen S, Small C E, Amb C M, et al. Inverted polymer solar cells with reduced interface recombination. Adv Energy Mater, 2012, 2: 13331337

10 Salleo A, Kline R J, Delongchamp D M, et al. Microstructural characterization and charge transport in thin films of conjugated polymers. 
Adv Mater, 2010, 22: 3812-3838

11 Lee O P, Yiu A T, Beaujuge P M, et al. Efficient small molecule bulk heterojunction solar cells with high fill factor via pyrene-directed molecular self-assembly. Adv Mater, 2011, 23: 5359-5363

12 Zhou J Y, Wan X J, Liu Y S, et al. Small molecules based on benzo [1,2-b:4,5-b']dithiophene unit for high-performance solution-processed organic solar cells. J Am Chem Soc, 2012, 134: 16345-16351

13 Lloyd M T, Anthony J E, Malliaras G G. Photovoltaics from soluble small molecules. Mater Today, 2007, 10: 34-41

14 Roncali J. Molecular bulk heterojunctions: An emerging approch to organic solar cells. Acc Chem Res, 2009, 42: 1719-1730

15 Li Y, Guo Q, Li Z, et al. Solution processable D-A small molecules for bulk-heterojunction solar cells. Energy Environ Sci, 2010, 3: 1427-1436

16 Tang W, Hai J, Dai Y, et al. Recent development of conjugated oligomers for high-efficiency bulk-heterojunction solar cells. Sol Energy Mater Sol Cells, 2010, 94: 1963-1979

17 Würthner F, Meerholz K. Systems chemistry approach in organic photovoltaics. Chem-Eur J, 2010, 16: 9366-9373

18 Hains A W, Liang Z, Woodhouse M A, et al. Molecular semiconductors in organic photovoltaic cells. Chem Rev, 2010, 110: 6689-6735

19 Walker B, Kim C, Nguyen T Q. Small molecular solution-processed bulk heterojunction solar cells. Chem Mater, 2011, 23: 470-482

20 Mishra A, Bäuerle P. Small molecule organic semiconductors on the move: Promises for future solar energy technology. Angew Chem Int Ed, 2012, 51: 2020-2067

21 Lin Y Z, Li Y F, Zhan X W. Small molecule semiconductors for high-efficiency organic photovoltaics. Chem Soc Rev, 2012, 41: 4245-4272

22 Shirota Y, Kageyama H. Charge carrier transporting molecular materials and their applications in devices. Chem Rev, 2007, 107: 953-1010

23 Cho N, Song K, Lee J K, et al. Facile synthesis of fluorine-substituted benzothiadiazole-based organic semiconductors and their use in solution-processed small-molecule organic solar cells. Chem Eur J, 2012, 18: 11433-11439

24 Li Z F, Dong Q F, Li Y W, et al. Design and synthesis of solution processable small molecules towards high photovoltaic performance. J Mater Chem, 2011, 21: 2159-2168

25 Dutta P, Yang W, Eom S H, et al. Development of naphtho [1,2-b:5,6-b']dithiophene based novel small molecules for efficient bulk-heterojunction organic solar cells. Chem Commun, 2012, 48: 573-575

26 Dutta P, Yang W, Eom S H, et al. Synthesis and characterization of triphenylamine flanked thiazole-based small molecules for high performance solution processed organic solar cells. Org Electron, 2012, 13: 273-282

27 Dutta P, Park H, Lee W H, et al. A crystalline D- $\pi$-A organic small molecule with naphtho[1,2-b:5,6-b']dithiophene-core for solution processed organic solar cells. Org Electron, 2012, 13: 3183-3194

28 Zeng S, Yin L, Ji C, et al. D- $\pi$-A- $\pi$-D type benzothiadiazole-triphenylamine based small molecules containing cyano on the $\pi$-bridge for solution-processed organic solar cells with high open-circuit voltage. Chem Commun, 2012, 48: 10627-10629

29 Lin Y, Cheng P, Liu Y, et al. Small molecules based on bithiazole for solution-processed organic solar cells. Org Electron, 2012, 13: 673-680

30 Shi Q, Cheng P, Li Y F, et al. A solution processable D-A-D molecule based on thiazolothiazole for high performance organic solar cells. Adv Energy Mater, 2012, 2: 63-67

31 Cheng Pei, Shi Q, Lin Y, et al. Evolved structure of thiazolothiazole based small molecules towords enhanced efficiency in organic solar cells. Org Electron, 2013, 14: 599-606

32 Lin Y, Cheng P, Liu Y, et al. Solution-processable small molecules based on thieno[3,4-c]pyrrole-4,6-dione for high-performance solar cells. Sol Energy Mater Sol Cells, 2012, 99: 301-307

33 Roncali J. Molecular bulk heterojunctions: An emerging approach to organic solar cells. Acc Chem Res, 2009, 42: 1719-1730

34 Shang H, Fan H, Liu Y, et al. A solution-processable star-shaped molecule for high-performance organic solar cells. Adv Mater, 2011, 23: $1554-1557$

35 Lin Y, Zhang Z G, Bai H, et al. A star-shaped oligothiophene endcapped with alkyl cyanoacetate groups for solution-processed organic solar cells. Chem Commun, 2012, 48: 9655-9657

36 Li Z, He G R, Wan X J, et al. Solution processable rhodanine-based small molecule organic photovoltaic cells with a power conversion efficiency of 6.1\%. Adv Energy Mater, 2012, 2: 74-77

37 Lee J W, Choi Y S, Jo W H. Diketopyrrolopyrrole-based small molecules with simple structure for high $V_{\text {oc }}$ organic photovoltaics. Org Electron, 2012, 13: 3060-3066

38 Huang J, Jia H, Li L, et al. Fine-tuning device performances of small molecule solar cells via the more polarized DPP-attached donor units. Phys Chem Chem Phys, 2012, 14: 14238-14242

39 Welch G C, Perez L A, Hoven C V, et al. A modular molecular framework for utility in small-molecule solution-processed organic photovoltaic devices. J Mater Chem, 2011, 21: 12700-12709

40 Sun Y M, Welch G C, Leong W L, et al. Solution-processed smallmolecule solar cells with 6.7\% efficiency. Nat Mater, 2012, 11: 44-48

41 Henson Z B, Welch G C, Bazan G C, et al. Pyridalthiadiazole-based narrow band gap chromophores. J Am Chem Soc, 2012, 134: 37663779

42 Takacs C J, Sun Y M, Welch G C, et al. Solar cell efficiency, self-assembly, and dipole-dipole interactions of isomorphic narrow-band-gap molecules. J Am Chem Soc, 2012, 134: 16597-16606

43 Kaafarani B R. Discotic liquid crystals for optoelectronic applications. Chem Mater, 2011, 23: 378-396

44 Takemoto K, Karasawa M, Kimura M. Solution-processed bulk-heterojunction solar cells containing self-organized disk-shaped donors. ACS Appl Mater Inter, 2012, 4: 6289-6294

45 Umeyama T, Takamatsu T, Tezuka N, et al. Synthesis and photophysical and photovoltaic properties of porphyrin-furan and -thiophene alternating copolymers. J Phys Chem C, 2009, 113: 10798-10806

46 Huang Y, Li L, Peng X, et al. Solution processed small molecule bulk heterojunction organic photovoltaics based on conjugated donor- acceptor porphyrin. J Mater Chem, 2012, 22: 21841-21844

47 Li L, Huang Y, Peng J, et al. Enhanced performance of solutionprocessed solar cells based on porphyrin small molecules with a diketopyrrolopyrrole acceptor unit and a pyridine addictive. J Mater Chem A, 2013, 1: 2144-2150

48 Kronenberg N M, Steinmann V, Bürckstümmer H, et al. Direct comparison of highly efficient solution- and vacuum- processed organic solar cells based on merocyanine dyes. Adv Mater, 2010, 22: 41934197

49 Steinmann V, Kronenberg N M, Lenze M R, et al. Simple, highly efficient vacuum-processed bulk heterojunction solar cells based on marocyanine dyes. Adv Energy Mater, 2011, 1: 888-893

50 Chen G, Sasabe H, Wang Z, et al. Co-evaporated bulk heterojunction solar cells with $>6.0 \%$ efficiency. Adv Mater, 2012, 24: 2768-2773

51 Lin L Y, Tsai C H, Wong K T, et al. Efficient organic DSSC sensitizers bearing an electron-deficient pyrimidine as an effective $\pi$ spacer. J Mater Chem, 2011, 21: 5950-5958

52 Chen Y H, Lin L Y, Lu C W, et al. Vacuum-deposited small-molecule organic solar cells with high power conversion efficiencies by judicious molecular design and device optimization. J Am Chem Soc, 2012, 134: 13616-13623

53 Fitzner R, Reinold E, Mishra A, et al. Dicyanovinyl-substituted oligothiophenes: Structure-property relationships and application in vacuum-processed small-molecule organic solar cells. Adv Funct Mater, 2011, 21: 897-910

54 Haid S, Mishra A, Uhrich C, et al. Dicyanovinylene-substituted selenophene-thiophene co-oligomers for small-molecule organic solar cells. Chem Mater, 2011, 23: 4435-4444

Open Access This article is distributed under the terms of the Creative Commons Attribution License which permits any use, distribution, and reproduction in any medium, provided the original author(s) and source are credited. 